\title{
Transformation of tourism and hospitality customers' perception of risk and customers' needs for control
}

Erdoğan Koç, Bilge Villi*

\begin{tabular}{|c|c|}
\hline & ABSTRACT \\
\hline Keywords: & Although tourism and hospitality have transformed to be much safer activities compared with the past \\
\hline Risk Perception, & with the developments in transportation and information technologies, they still involve many risks. \\
\hline Uncertainty, & This review paper explains and discusses the influence of the perception of risk on consumer behaviour \\
\hline Hospitality, & in tourism and hospitality and strategies that can be used to reduce consumers' risk perceptions. As \\
\hline Types of Risks, & eliminating or reducing consumers' risk perceptions help tourism and hospitality businesses attract \\
\hline Control, & more customers and maintain them, understanding concepts of risk and control may enable tourism and \\
\hline Culture, & hospitality businesses to establish competitive advantage over their competitors. With this background \\
\hline Personality & $\begin{array}{l}\text { in mind, the study introduces the concept of risk and the types of risks that may be associated with } \\
\text { tourism and hospitality activities. The study also explains factors such as personality, personal }\end{array}$ \\
\hline Article History: & characteristics which may influence customers' risk perceptions, and how these influences may take \\
\hline Submitted: 02.02.2021 & place in various contexts. Then, the study explains the theory of control and types of control which may \\
\hline Accepted: 07.06.2021 & be used to reduce consumers' risk perceptions. \\
\hline
\end{tabular}

Doi: https://doi.org/10.31822/jomat.2021-6-2-117

\section{Introduction}

Etymologically the word travel comes from the French word travail, which means to operate under great duress and endure hardship, very tiring labour and a great danger (Koc, 2000). The word travail also traditionally referred to an instrument of torture. Before the modernisation of transportation methods, travel was associated with adventure and it had inherent connotations of risk and danger. For travel and tourism to become a mass activity these above connotations attributed to travel had to change.

The purchase of services, in general, tend to be riskier for customers than the purchase of tangible products (Laroche et al., 2003; Cunningham et al., 2005; Nordin et al., 2011; Dorothea and Benkenstein, 2014; Villi and Koc, 2018; Koc, 2020a). This is mainly to do with the general service characteristics of inseparability, heterogeneity, intangibility, and perishability (Parasuraman et al., 1988) as these characteristics increase uncertainty and ambiguity, eventually leading to a relatively higher level of perception of risk by the customers. Furthermore, tourism and hospitality services may involve encounters with many unknowns in the form of destinations, people, accommodation, transport, food, etc. (Koc, 2006). Hence, the perception of risk has wide spread implications, influencing a wide variety of issues, both for the demand (customer) and supply (service provider) sides.

The unexpectedness, arising out of uncertainty, of an event, exacerbates people's feelings towards that event, whether its outcome is a positive or a negative one. Research shows that unexpected gains cause more pleasure than expected gains, and unexpected losses cause more displeasure or pain than the expected losses (Mellers et al., 1997). Mellers et al. (1997) found that a surprising $\$ 9$ win was more enjoyable than an expected $\$ 17$ win, and likewise, a surprising $\$ 9$ loss was more painful than an expected $\$ 17$ loss. Koc (2017) argues that the occurrence of service recovery paradox (i.e. customer's post-failure satisfaction is greater than pre-failure satisfaction due to the service recovery) and customer delightment (surprising a customer

*Corresponding Author $\quad$ Review paper Erdoğan Koç: Professor, Bahcesehir University, Istanbul, Turkey, Email: erdogan.koc@eas.bau.edu.tr, Orcid Id: 0000-0003-3183-2574 (1D

Bilge Villi: Dr., Balikesir University, Istanbul, Turkey, Email: bilgevilli@balikesir.edu.tr, Orcid Id: 0000-0002-1175-2043 iD 
Table 1: Types of Risk in Tourism and Hospitality Adapted from Koc (2020a)

\begin{tabular}{|c|c|c|}
\hline Type of Risk & Some of the Key Issues & Questions \\
\hline $\begin{array}{l}\text { Physiological - Physical } \\
\text { Risk }\end{array}$ & $\begin{array}{l}\text { Health, well-being, safety, security, } \\
\text { hygiene, threat. }\end{array}$ & $\begin{array}{l}\text { Would it be safe as the hotel is in nature, kilometers away from the } \\
\text { nearest town? } \\
\text { Would the staff be paying attention to hygiene requirements? } \\
\text { Would the food in the restaurant be fresh, hygienic, and healthy? }\end{array}$ \\
\hline Financial or monetary risk & $\begin{array}{l}\text { Money, Losing, Wasting, Cheating, } \\
\text { Swindle }\end{array}$ & $\begin{array}{l}\text { Can I afford to stay at this hotel? } \\
\text { Would there be extra charges? } \\
\text { Is it worth the money they charge? } \\
\text { Is it sensible to pay for the local trips beforehand? }\end{array}$ \\
\hline Social risk & $\begin{array}{l}\text { Fashionable, popular, high, showing } \\
\text { off, class, prestige, old-fashioned, } \\
\text { tasteless, low class, humiliating, }\end{array}$ & $\begin{array}{l}\text { Would people be impressed when they see my photos on social } \\
\text { media taken in this restaurant? } \\
\text { Would people envy me because of the cruise I am taking? } \\
\text { Does this destination have a poor image in the eyes of people? }\end{array}$ \\
\hline Ego or psychological risk & $\begin{array}{l}\text { Self-esteem, contentedness, feelings of } \\
\text { guilt, regret, }\end{array}$ & $\begin{array}{l}\text { Does the business operate in a socially responsible manner? } \\
\text { Am I happy to be here? }\end{array}$ \\
\hline $\begin{array}{l}\text { The performance or } \\
\text { Functional Risk }\end{array}$ & $\begin{array}{l}\text { Performance, waiting time, ingredients, } \\
\text { contents }\end{array}$ & $\begin{array}{l}\text { Is it all-inclusive? } \\
\text { Do they use all those ingredients? Are the dishes as delicious as } \\
\text { they look? }\end{array}$ \\
\hline Time Risk & $\begin{array}{l}\text { Wasting time, irreversible, reversible, } \\
\text { revocable, irrevocable, money-back } \\
\text { guarantee }\end{array}$ & $\begin{array}{l}\text { How effective is their refund policy? } \\
\text { What if don't like the food there? } \\
\text { What if the whole holiday turns out to be a failure? }\end{array}$ \\
\hline
\end{tabular}

Source: Koc, E. (2020a). Cross-Cultural Aspects of Tourism and Hospitality: A Services Marketing and Management Perspective. London: Routledge.

by exceeding her/his expectations) is to do with this unexpectedness. When the service recovery paradox and customer delightment occur, the surprise, or the unexpectedness of positive gains, cause elicitation of excessively/exacerbated positive emotions. Likewise, the unexpectedness of service failures may cause excessive negative feelings for the customers.

\section{The Concept of Risk and the Types of Risk}

Risk can be defined as the probability or the possibility of harm or damage. In other words, the risk is to do with the probability of a loss, an injury, or an unwanted consequence (Häyry and Takala, 1998). The feeling of uncertainty tends to increase the perception of risk as uncertainty may inherently contain possible unpleasant consequences. As people perceive risks as threats to their survival and well-being, they tend to try to avoid risks and prefer to refrain from engaging in further action (Koc, 2013). Koc (2020a) summarises the risks associated with tourism and hospitality as shown in Table 1.

The various risks described in Table 1 may influence consumer decision-making differently and may require different actions and strategies to be taken by the tourism and hospitality managers. Hence, the managers in these businesses need to be aware of various types of risks (Suciu et al., 2020) as unless eliminated or reduced they would stand as a major barrier between the customer and the business (Dorothea and Benkenstein, 2014; Koc, 2020a).

\section{Factors Influencing Risk Perception and Risk- Taking Behaviours}

Perception of risk and risk-taking behaviours of people may be influenced by a wide variety of factors such as physiological, personal, and cultural. As stated above, while most people tend to avoid risks, certain people, who may be classified as risk-takers, or risk lovers, may be comfortable or happy to take risks, to a certain extent, in certain situations. In terms of physiological factors, even a parasite (See the Information Box below) may influence risk perception and risk-taking behaviours of people.
Information Box:
Risk-Taking and Toxoplasma Gondii Parasite
It is known that Toxoplasma gondii, a parasite that can infect people, and also various animals such as cats, rats, and dogs, reduce the perception of risk in the brain (Koc, 2020a). Toxoplasma gondii, often referred to as toxo, reduces fear through dysfunctioning of the cortex and amygdala in the brain, the part of the brain responsible for detecting fear and preparing for emergency events. Toxoplasma gondii infected people and animals do not tend to fear and be more likely to take risks. Research shows that people who have Toxoplasma gondii engage more in traffic accidents as they are more likely to take engage in risky behaviours (Flegr, 2013). On the positive side, Johnson et al.'s (2018) study found that Toxoplasma gondii infection was a consistent positive predictor of entrepreneurial activity and entrepreneurial intentions. Likewise, people who engage in extreme sports such as sky diving, mountain cycling and climbing, and bungee jumping, and people who engage in adventure holidays such as rafting down the Grand Canyon, walking the Inca Trail, or climbing Kilimanjaro, or trekking and hiking may be Toxoplasma gondii infected (Koc, 2020a). 
Also, according to risk-sensitivity theory individuals may engage in risky decisions depending on their needs. If people feel that they are unable to meet their needs through safer, lower-risk means, they may be more likely to engage in risk-taking behaviours (Kacelnik and Bateson, 1996; Mishra et al., 2017; Li et al., 2019). This means that when people need something, and especially when the strength of that need is relatively high, they may shift from risk-aversion to risk-taking, with the belief that risky options, though slim, may create for them at least some chance to satisfy their needs (Mishra et al., 2014; $\mathrm{Li}$ et al., 2019). In other words, individuals can make risk-sensitive decisions depending on the level of motivation they have to satisfy those particular needs. This means that people are more likely to take risks if they feel that those needs are unlikely to be met through safer, low-risk means (Kacelnik and Bateson, 1996, 1997; Mishra et al., 2017; Li et al., 2019).

\section{Personal Factors: Personality and Gender}

In terms of the personal factors, personality characteristics of people (e.g. openness to experience, conscientiousness, extraversion, agreeableness, and neuroticism), may influence people's attitudes towards risk (Koc, 2019 and 2020a). For instance, research shows that people who have a high level of extraversion and openness to experience, and lower levels of conscientiousness as personality characteristics, are more likely to be comfortable with risk-taking and more capable of enduring in uncertain and ambiguous environments (Tok, 2011; McGhee et al.,2012). Moreover, other sub-traits of personality may also play an important role in risk-taking behaviours of people. Gupta et al's (2006) study found that factors such as disinhibition, boredom, susceptibility, cheerfulness, and excitability, as well as low levels of conformity, and self-discipline were more strongly associated with risk-taking behaviours, such as gambling. Additionally, researchers (e.g. Pizam et al. 2004; Reisenger and Mavondo, 2005; Gray and Wilson, 2009; Williams and Baláž, 2013) demonstrated that there is a significant relationship between sensation seeking as a personality trait and risk-taking.

Another factor that influences people's responses towards risk is their gender (Meyers-Levy and Loken, 2015; Koc, 2020b). Due to males' mating concerns, their search for status, and their achievement orientation, in general, they tend to be more comfortable with taking a risk, and consequently, they are more likely to take a risk than females (Ellis, 2006; Charness and Gneezy, 2012; Ertac and Gurdal, 2012). On the other hand, due to their communal orientation, females, in general, tend to be more risk-averse, cautious, and avoidance-based than males (Fischer and Mosquera, 2001; Meyers-Levy and Locken, 2015; Koc, 2020b).

Culture also influences consumers' risk perceptions, attitudes towards risk, and their overall behaviours. Hofstede (2001) developed a cross-cultural variable, called uncertainty avoidance, to measure, classify and compare countries in terms of the degree of comfort members of a society feel in unfamiliar or unstructured situations and the degree to which a society tries to control the uncontrollable. The presence of cultural distance between the service provider in tourism and hospitality increases the perception of risk (Shenkar, 2001; Litvin et al, 2004). Ahmed and Krohn (1993) demonstrated that there are plenty of Japanese owned hotels in Hawaii, as many Japanese believe that only the Japanese can fully meet their needs.

\section{Implications of Risk Perception and Uncertainty Avoidance for Consumer Behaviour}

As stated above customers tend to perceive the purchasing of services as riskier than the purchasing of tangible products (Nordin et al., 2011; Dorothea and Benkenstein, 2014). Hence, the loyalty of customers towards services is higher than their loyalty to tangible products (Zeithaml, 1981; Setó-Pamies, 2012). This is mainly to do with the heterogeneity/variability inherent in services (Koc, 2017). Moreover, the switching costs of services (financial and non-financial costs, e.g. search costs in the form of effort, etc.) may be relatively higher compared with tangible products (Ruyter et al., 2001; Koc, 2017). Additionally, the availability of substitutes/alternatives, or as often referred to as repertoire, consideration set or the evoked set, i.e. the range of different service brands/products available for purchase and use by consumers may be relatively limited compared with tangible products (Koc, 2017).

Risk perception of customers may influence a wide variety of aspects of tourism and hospitality, ranging from their responses to all marketing mix elements $(7 \mathrm{Ps})$ to their general perceptions of and responses towards service quality perceptions and individual service quality dimensions. However, here the influences of risk perception on customers' product choices and information collection, loyalty 
and complaint behaviour, price, and marketing communications will be explained as examples.

\section{Product Choices and Information Collection}

As stated above, behaviours of consumers are very much influenced by the cultures they come from. For instance, as opposed to people from lowuncertainty avoidance cultures (e.g. Singapore, Sweden, Hong Kong, United Kingdom, United States, Norway, and New Zealand) people from high-uncertainty avoidance cultures are more likely to feel uncomfortable and threatened in unstructured, uncertain, and unfamiliar environments. These people tend to value structure and predictability more than other people (Litvin et al., 2004). Moreover, tourism and hospitality customers from high-uncertainty avoidance cultures are more likely to have a higher preference for their cuisine and are more likely to have food neophobia (fear of eating new or unfamiliar foods) (Koc, 2020a). Also, consumers who are from highuncertainty avoidance cultures tend to collect more information, use more personal sources of information (e.g. brick-and-mortar travel agencies rather than on-line travel agencies and Internet sources), travel in larger groups, prefer safer activities (e.g. favour slow-paced, participate in more indoor activities, visiting friends and relatives, shopping and staged events (Money and Crotts, 2003; Manrai and Manrai, 2011; Chen and Jiang, 2019). Sabiote-Ortiz et al. (2016) demonstrated that travel agencies cause lower levels of uncertainty for customers due to personal interaction, and the control they offered to the customers. Tourism and hospitality customers with lower levels of risk perception (e.g. customers from the UK) do not tend to associate online information with high risk, while customers with higher levels of risk perception (e.g. customers from France, Belgium, and Italy) preferred travel agencies as low-risk information sources (Frias et al.,2012). While the risk perception may influence the types of tourism and hospitality activities, it may also influence the design of these particular services and the servicescape. For instance, Zein (2015) puts forward that in low-uncertainty avoidance cultures children are left on their own to play, while in high-uncertainty avoidance cultures children are carefully looked after, and are never let out of sight. For instance, Koc (2016a) argued that IKEA's Smaland application would not work in Turkey due to the high-risk perception and uncertainty avoidance of Turkish people. Smaland, named after the region in southern Sweden where IKEA originated, is a supervised children's area in IKEA stores, with a forest-themed playground equipped with a ball pit, where parents can leave their children with caretakers while they shop for as long as 90 minutes, free of charge. Koc (2020) argues the design of servicescape and amenities (e.g. the swimming pool; children's playgrounds, etc.) need to take into account the customers' level of risk perceptions.

\section{Customer Loyalty and Complaint Behaviour}

From a customer loyalty perspective, Ndubisi et al. (2012) demonstrated that when customers' risk perceptions were low (e.g. when they are from lowuncertainty avoidance cultures) their loyalty towards service providers appeared to be low. On the other hand, customers with higher levels of risk perceptions tend to stick to and be loyal towards the service providers who satisfy their needs. In general, customers frequently engage in varietyseeking behaviour when they purchase hedonic experiences like tourism and hospitality (Bigné, et al., 2009).

However, for customers with higher levels of risk perception, the thrill of seeking variety tends to be lower than the motivation to avoid risks. Hence, service providers' efforts to increase customer loyalty may work better with customers with highrisk perceptions.

Moreover, tourism and hospitality customers with higher levels of risk perception are more likely to praise the service provider and less likely to make a complaint (Tsaur et al., 2005). Customers with higher risk perceptions are less likely to switch to other services even if they encountered service failures with the current service provider. As in the proverb "better the devil you know than the devil you don't", these customers may think that switching to other service providers may involve further uncertainties and risks. Hence, these customers may refrain from switching to other service providers (Koc, 2020a). However, it must be borne in mind that, though these customers may not switch, yet other negative consequences may occur such as engaging in negative word-of-mouth communication, etc.

It was explained above that tourism and hospitality decisions were risky due to the many unknowns, uncertainties, and general service characteristics such as intangibility and heterogeneity. Further, the purchase of particular types of touristic products/services may involve spending large sums of money on something which cannot be fully perceived before it is experienced. Though duration wise, tourism and travel 
activities may represent a relatively smaller proportion of time in a year, they may cost large amounts of money. For instance, Koc (2000) argues that while a week's holiday may represent less than $2 \%$ of the time in a fifty-two-week year, this holiday may cost as much as $10 \%$ or more of the annual income of the customer. Research shows that while an open demonstration of a tourism and hotel establishment's pricing information influenced risk aversive customers (e.g. customers from high-uncertainty avoidance cultures such as South Korea) positively, it had no effect on customers from low-uncertainty avoidance cultures (e.g. the USA) (Mattila and Choi, 2006).

\section{Marketing Communications}

As all promotional tools (advertising, public relations, sales promotion, and personal selling) are used to convey messages to the customers, when designing messages aimed at the target market, customers' levels of risk perceptions need to be taken into account. For instance, advertising messages need to use themes that are appropriate for customers who have high levels of risk perception. Albers-Miller and Gelb (1996) proposed three advertising appeals most relevant to customers from highly risk-averse cultures. These are i) safety (carefulness, guarantees, caution, and stability), ii) tamed (compliant, faithful, reliable, responsible, domesticated, docile, and civilised) and iii) durable (long-lasting, permanent, stable, strong, powerful, tough and enduring). However, one must be careful when conveying a safety message to customers. Rittichainuwat (2013) demonstrated that manifest safety measures and messages may increase risk perceptions of customers and scare them, especially the customers who are risk-averse. Rittichainuwat (2013) found that an increase in safety measures frightened about $33 \%$ of tourists. This may be attributable to priming (Koc, 2016a), or co-variance bias, since the safety measures, or cues relating to safety in communications, may act as signals or reminders for the risks and threats looming.

\section{Control as a Risk Reduction Strategy}

Customers perceive risks as uncertainties that cause helplessness or a lack of control against likely negative events that may take place. Hence, people, in general, prefer to have control in almost all situations in order to reduce the level of uncertainty and increase predictability (Ding et al., 2016; Koc and Boz, 2017). This is because of the absence of uncertainties and risk and the presence of predictability and control foster the survival of human beings.
Information Box:

Risk-Taking and Pro-Social Behaviour

According to Kenrick and Griskevicius (2013) exposure to fear (risk) increases people's tendency to engage in social behaviour. In other words, when people perceive risks or threats, their tendency to be part of a group, and their tendency to conform to a group increases. Kenrick and Griskevicius's (2013) research showed that when people were shown horror movies their tendency to like advertisements and commercials that implied togetherness and being with a crowd of people increased. On the other hand, people's tendency to like advertisements and commercials which implied being alone and separated from a group increased when they were shown romantic movies. This is because human beings since the early primitive ages have been aware that they would be unable to survive on their own. Even in today's modern world, loneliness and social isolation are among the high-risk factors for mortality (Holt-Lunsad et al., 2015), though for mainly psychological reasons, rather than the physiological ones.

Reducing risk and maintaining predictability has been so important that they have been even instrumental in the establishment of the main pillars of today's modern society. This is because the main motivation behind the move from a hunter-gatherer to agrarian society, around 8000 BCE in Mesopotamia, was based on the need to reduce risk and increase predictability, by having control over certain aspects of life (Harari, 2016; Koc and Boz, 2017). In the agrarian society, people tried to establish systems and life styles within which they were able to have control. According to Miller's (1979) "Minimax Hypothesis" control allows the individual to minimise the maximum danger/risk or discomfort. This means that the individual with control can attribute the cause of relief from the aversive event to a stable internal source, the self, rather than a less stable external source (Chen and Cooper, 2014). This means that when an individual has control over various events taking place in her/his environment, s/he may be in a position to ensure encountering a lower level of maximum danger than someone who does not have control (Koc and Boz, 2017).

In line with Miller's (1979) Minimax Hypothesis, Kahneman and Tversky's (1979) Prospect Theory demonstrates that human beings ascribe more value to not losing than the value they ascribe to winning. This is because losing may place people in jeopardy, preventing their survival, i.e. the primary goal of all human beings. In line with people's desire to control their environments, Averill (1979) suggested three types of control as i) cognitive, ii) behavioural, and iii) decisional.

Cognitive control (See Table 2) is about the control is to do with having sufficient information about 
the future, and being confident about the future (Faranda, 2001; Koc and Boz, 2017). Cognitive control ensures the evasion of encountering negative surprises (Faranda, 2001; Koc and Boz, 2017). In tourism and hospitality activities customers may be said to have control if they have been provided informed appropriately with the necessary details regarding prices, payments, and service features. For instance, tourists who are sensitive towards risk (e.g. due to their personal, personality, and cultural characteristics) tend to be more likely to purchase pre-paid all-inclusive packages to ensure that they have maximum control over their holidays (Koc, 2006). Likewise, hospitality establishments such as restaurants and cafes may clearly display their menus (in terms of all details regarding prices, ingredients, etc.) to allow their targeted consumers to have cognitive control (See Table 2).

As another type of control, decisional control (See Table 2) can be defined as the ability and the freedom of a consumer to make her/his own product/service decisions according to her/his needs and desires (Koc, 2013; Koc and Boz, 2017). Hence, decisional control also involves having a sufficient number of alternatives and being free from the pressures and intrusion of others when making decisions. The availability of alternatives for the customers enables the customers to make their choices more freely, choices that would match their needs better. For instance, the availability of several alternative holiday packages, and the right to make alterations to these packages according to one's needs would allow customers to have decisional control. Likewise, all-inclusive holidays with open buffet meals can allow customers to have decisional control in terms of choosing what to eat and the amount of food they would like to have. Burger King's "Have it Your Way" slogan is also another example of decisional control reminding customers that they can make alterations to food items according to their specific needs and wants.

However, decisional control may often cause a Pavlovian conditioning called the illusion of control (Heider, 1958; Langer, 1975; Unzicker, 1999; Koc, 2013). As a cognitive bias or an attributional error, Illusion of control is the tendency of an individual to overestimate her/his ability to control events and the attaching ascribing positive qualities to her and his decision. The illusion of control creates a feeling of illusory superiority or an optimistic bias and resulting in inflated self-efficacy beliefs (Lovallo and Kahneman, 2003). The illusion of control also increases the amount of value attached to and liking for the choices the individual makes (Bandura, 1997; Weiner, 2000; McKenna and Albery, 2001). As a similar phenomenon to the illusion of control, the endowment or divestiture effect (Thaler, 1980) is the attribution of increased value or increased liking for the choices an individual makes (Kahneman et. al, 1991).

Koc (2013 and 2016b) found that decisional control in all-inclusive open-buffet holidays caused customers to have an illusion of control. Customers on these holidays were more likely to attach more value to the food they chose from the open buffet restaurants and liked the food they chose more than they normally did. As a result, tourists on allinclusive open-buffet holidays tended to consume more food, both quantity, and variety wise, than they did in their usual daily lives. Koc (2013 and 2016b) showed that all-inclusive holidays with open buffet restaurants had the potential to cause obesity among the customers.

As the third type of control, behavioural control (Table 2) is the ability of a customer to influence a situation or an event. Hence, for instance, behavioural control can be described as an ability of a customer to cancel her/his purchase of a service (a holiday reservation or a restaurant booking)

Table 2: The Three Types of Control and the Recommended Courses of Actions

\begin{tabular}{|l|l|}
\hline Type of Control & Recommended Courses of actions \\
\hline Cognitive Control & $\begin{array}{l}\text { Provision of all the necessary information to the customers. Making information more accessible to customers. } \\
\text { Making sure that customers know various aspects of the tourism and hospitality service such as the price, payment and } \\
\text { package details, service times, etc. } \\
\text { Forming standard product packages with fixed prices - e.g. all-inclusive holidays package holidays, set menus in a } \\
\text { restaurant, etc. } \\
\text { Eliminating the heterogeneity of services as much as possible and providing more standardised services. }\end{array}$ \\
\hline $\begin{array}{l}\text { Decisional } \\
\text { Control }\end{array}$ & $\begin{array}{l}\text { Offering as many alternatives and choices as possible for the customers. } \\
\text { Allowing customers to take part in the design of the services to make services fit their specific needs. } \\
\text { Allowing customers to make their choices freely without the intrusion of the sales staff. Avoiding hard-sell tactics. }\end{array}$ \\
Control & $\begin{array}{l}\text { Offering customers opportunities to cancel their purchase decisions when they wish to do so. } \\
\text { Making sure that customers trust the business in terms of refunds. Making sure that customers believe that they can get } \\
\text { their money back when/if they cancel. }\end{array}$ \\
\hline
\end{tabular}


without incurring any, or any significant costs/fines (See Table 2). Koc (2013) argues that businesses that allow cognitive, decisional, and behavioural control to their customers may be in a position to establish a competitive advantage over their competitors.

\section{Conclusions}

This review paper explains how consumers' risk perceptions may influence their beliefs, attitudes, and behavioural responses when they make purchasing and consumption decisions in tourism and hospitality. The study shows that unless eliminated or reduced, risk stands as a barrier between the customer and the service provider. Understanding the concept of risk, its main types, the factors influencing consumers' risk perceptions, and the strategies which may be used to eliminate or reduce risk may help practitioners in a number of ways. First, they may be able to attract more customers. Secondly, they may be able to expand the market they target. Thirdly, they may satisfy the needs of the customers better and they may be able to maintain and keep more of their customers. Therefore, understanding various aspects of risk and control relating to tourism and hospitality services may enable tourism and hospitality businesses to establish competitive advantage. For example; consumers should be clearly informed about the costs or legal obligations that they must face after purchasing the related product and service. Additionally, giving consumers the opportunity to return the product if they are not satisfied with it after the purchase will be a remarkable factor reducing the risk uncertainty.

\section{References}

Ahmed, Z. U., \& Krohn, F. B. (1993). Understanding the unique consumer behavior of Japanese tourists. Journal of Travel \& Tourism Marketing, 1(3), 7386.

Albers-Miller, N., \& Gelb, B. (1996). Business advertising appeals as a mirror of cultural dimensions: A study of eleven countries. Journal of Advertising, 25, 57-70.

Averill, J. R. (1973). Personal control over aversive stimuli and its relationship to stress. Psychological bulletin, 80(4), 286-303.

Bandura, A. (1997). Self-efficacy: The exercise of control. New York: W. H. Freeman and Company.

Bigné, E. J., Sanchez, I., \& Andreu, L. (2009). The role of variety seeking in short and long run revisit intentions in holiday destinations. International Journal of Culture, Tourism and Hospitality Research, 3(2), 103-115.
Charness, G., \& Gneezy, U. (2012). Strong evidence for gender differences in risk taking. Journal of Economic Behavior \& Organization, 83(1), 50-58

Chen, P. Y., \& Cooper, C. (Eds.). (2014). Wellbeing: a complete reference guide, work and wellbeing (Vol. 3). John Wiley \& Sons.

Chen, Y., \& Jiang, K. (2019). A multiple indicators multiple causes (mimic) model of the behavioral consequences of hotel guests. Tourism management perspectives, 30, 197-207.

Cunningham, L. F., Gerlach, J. H., Harper, M. D., \& Young, C. E. (2005). Perceived risk and the consumer buying process: internet airline reservations. International Journal of Service Industry Management, 16(4), 357-372.

Ding, Y., Ding, Y., Keh, H. T., \& Keh, H. T. (2016). A reexamination of service standardization versus customization from the consumer's perspective. Journal of Services Marketing, 30(1), 16-28.

Dorothea Brack, A., \& Benkenstein, M. (2014). Responses to other similar customers in a service setting-analyzing the moderating role of perceived performance risk. Journal of Services Marketing, 28(2), 138-146.

Ellis, L. (2006). Gender differences in smiling: An evolutionary neuroandrogenic theory. Physiology \& Behavior, 88(4), 303-308.

Ertac, S., \& Gurdal, M. Y. (2012). Deciding to decide: Gender, leadership and risk-taking in groups. Journal of Economic Behavior \& Organization, 83(1), 24-30.

Faranda, W. T. (2001). A scale to measure the cognitive control form of perceived control: Construction and preliminary assessment. Psychology \& Marketing, 18(12), 1259-1281.

Fischer, A. H., \& Mosquera, P. M. R. (2001). What concerns men? Women or other men ?: A critical appraisal of the evolutionary theory of sex differences in aggression. Psychology, Evolution \& Gender, 3(1), 5-25.

Flegr, J. (2013). Influence of latent Toxoplasma infection on human personality, physiology and morphology: pros and cons of the Toxoplasmahuman model in studying the manipulation hypothesis. Journal of experimental Biology, 216(1), 127-133.

Gupta, R., Derevensky, J. L., \& Ellenbogen, S. (2006). Personality characteristics and risk-taking tendencies among adolescent gamblers. Canadian Journal of Behavioural Science/Revue canadienne des sciences du comportement, 38(3), 201-203.

Gray, J. M., \& Wilson, M. (2009). The relative risk perception of travel hazards'. Environment and Behavior 41(2), 185-204 
Harari, Y. N. (2016). Homo Deus: A brief history of tomorrow. Random House.

Häyry, M., \& Takala, T. (1998). "Genetic Engineering and the Risk of Harm." Medicine, Health Care and Philosophy 1 (1998): 61-64.

Heider, F. (1958) The Psychology of Interpersonal Relations. New York: John Wiley \& Sons.

Hofstede, G. (2001). Culture's consequences, second edition: comparing values, behaviors, institutions and organizations across nations. Thousand Oaks: Sage Publications.

Johnson, S. K., Fitza, M. A., Lerner, D. A., Calhoun, D. M., Beldon, M. A., Chan, E. T., \& Johnson, P. T. (2018). Risky business: linking Toxoplasma gondii infection and entrepreneurship behaviours across individuals and countries. Proceedings of the Royal Society B: Biological Sciences, 285(1883), 20180822

Kacelnik, A., \& Bateson, M. (1997). Risk-sensitivity: crossroads for theories of decision-making. Trends Cogn. Sci. 1, 304-309.

Kahneman, D., \& Tversky, A. (1979). Prospect theory: An analysis of decision under risk. Econometrica: Journal of the econometric society, 263-291.

Kahneman, D., Knetsch, J. L., \& Thaler, R. H. (1991). Anomalies: The endowment effect, loss aversion, and status quo bias. The journal of economic perspectives, 193-206.

Kenrick, D. T., \& Griskevicius, V. (2013). The rational animal: How evolution made us smarter than we think. Basic Books.

Koc, E. (2000). The role and potential of marketing communications in the Turkish domestic tourism market (Unpublished Doctoral dissertation, Oxford Brookes University).

Koc, E. (2006). Total quality management and business excellence in services: The implications of allinclusive pricing system on internal and external customer satisfaction in the Turkish tourism market. Total Quality Management \& Business Excellence, 17(7), 857-877.

Koc, E. (2013). Inversionary and liminoidal consumption: Gluttony on holidays and obesity. Journal of Travel \& Tourism Marketing, 30(8), 825-838.

Koc, E. (2016a). Tüketici Davranışı ve Pazarlama Stratejileri: Global ve Yerel Yaklaşım (Vol. 7). Ankara, Turkey: Baskı, Seçkin Yayınları.

Koc, E. (2016b). Food consumption in all-inclusive holidays: illusion of control as an antecedent of inversionary consumption. Journal of Gastronomy and Tourism, 2(2), 107-116.

Koc, E. (2017). Service failures and recovery in tourism and hospitality: A practical manual. Wallingford, Oxford: CABI.
Koc, E. (2019). Service failures and recovery in hospitality and tourism: A review of literature and recommendations for future research. Journal of Hospitality Marketing \& Management, 28(5), 513-537.

Koc, E. (2020a). Cross-Cultural Aspects of Tourism and Hospitality: A Services Marketing and Management Perspective. London: Routledge.

Koc, E. (2020b). Do women make better in tourism and hospitality? A conceptual review from a customer satisfaction and service quality perspective. Journal of Quality Assurance in Hospitality \& Tourism, 21(4), 402-429.

Koc, E., \& Boz, H. (2017). Development of Scales to Measure Customers' Willingness to Have Control and the Control Offered by Service Businesses. Ecoforum, 6. (3), 27-35

Langer, E. J. (1975). The illusion of control. Journal of Personality and Social Psychology, 32, 311-328

Laroche, M., Bergeron, J., \& Goutaland, C. (2003). How intangibility affects perceived risk: the moderating role of knowledge and involvement. Journal of services marketing, 17(2), 122-140.

Li, Y. J., Lu, S., Lan, J., \& Jiang, F. (2019). Feel Safe to Take More Risks? Insecure Attachment Style Increases Consumer Risk-Taking Behavior. Frontiers in psychology, 10, 874.

Litvin, S. W., Crotts, J. C., \& Hefner, F. L. (2004). Crosscultural tourist behaviour: a replication and extension involving Hofstede's uncertainty avoidance dimension. International Journal of Tourism Research, 6(1), 29-37.

Lovallo, D., \& Kahneman, D. (2003). Delusions of success. Harvard Business Review,57-63. July.

Manrai, L. A., \& Manrai, A. (2011). Hofstede's cultural dimensions and tourist behaviors: A review and conceptual framework. Journal of Economics, Finance \& Administrative Science, 16(31), 23.

Mattila, A. S., \& Choi, S. (2006). A cross-cultural comparison of perceived fairness and satisfaction in the context of hotel room pricing. International Journal of Hospitality Management, 25(1), 146153.

McGhee, R. L., Ehrler, D. J., Buckhalt, J. A., \& Phillips, C. (2012). The relation between five-factor personality traits and risk-taking behavior in preadolescents. Psychology, 3(08), 558.

McKenna, F. P., \& Albery, I. P. (2001). Does unrealistic optimism change following a negative experience? Journal of Applied Social Psychology, 31 6, 11461157.

Mellers, B. A., Alan Schwartz, Katty Ho, \& Ilana Ritov. (1997), "Decision Affect Theory: Emotional 
Reactions to the Outcomes of Risky Options," Psychological Science, 8 (6), 423-429.

Meyers-Levy, J., \& Loken, B. (2015). Revisiting gender differences: What we know and what lies ahead. Journal of Consumer Psychology, 25(1), 129-149.

Miller, S. M. (1979). Controllability and human stress: Method, evidence and theory. Behaviour Research and Therapy, 17, 287-304.

Mishra, S., Barclay, P., \& Sparks, A. (2017). The relative state model: integrating need-based and abilitybased pathways to risk-taking. Pers. Soc. Psychol. Rev. 21, 176-198.

Money, B., \& J. Crotts (2003). "The Effect of Uncertainty Avoidance on Information Search, Planning and Purchases of International Travel Vacations." Tourism Management, 24 (2): 191-202.

Ndubisi, N. O., Malhotra, N. K., Ulas, D., \& Ndubisi, G.C. (2012). "Examining Uncertainty Avoidance, Relationship Quality, and Customer Loyalty in Two Cultures". Journal of International Consumer Marketing. 24 (5): 320-337.

Nordin, F., Kindström, D., Kowalkowski, C., \& Rehme, J. (2011). The risks of providing services: Differential risk effects of the servicedevelopment strategies of customisation, bundling, and range. Journal of Service Management, 22(3), 390-408.

Parasuraman, A., Zeithaml, V. A. \& Berry, L. L. (1988). SERVQUAL: a multiple-item scale for measuring consumer perceptions of service quality. Journal of Retailing. 64 (1): 12-40.

Rittichainuwat, B. N. (2013). Tourists' perceived risks toward overt safety measures. Journal of Hospitality \& Tourism Research, 37(2), 199-216.

Ruyter, K., Wetzels, M., \& Kleijnen, M. (2001). "Customer Adoption of eservice: an Experimental Study". International Journal of Service Industry Management, 12 (2), 184-207.

Sabiote-Ortiz, C. M., Frías-Jamilena, D. M., \& Castañeda-García, J. A. (2016). Overall perceived value of a tourism service delivered via different media: A cross-cultural perspective. Journal of Travel Research, 55(1), 34-51.

Setó-Pamies, D. (2012). Customer loyalty to service providers: examining the role of service quality, customer satisfaction and trust. Total Quality Management \& Business Excellence, 23 (11-12), 1257-1271.

Shenkar, O. (2001). Cultural distance revisited: towards a more rigorous conceptualization and measurement of cultural differences. Journal of International Business Studies 32(3): 519-535.

Suciu, M. C., Noja, G. G., \& Cristea, M. (2020). Diversity, Social Inclusion and Human Capital
Development as Fundamentals of Financial Performance and Risk Mitigation. Amfiteatru Economic, 22(55), 742-757.

Thaler, R. (1980). Toward a positive theory of consumer choice. Journal of Economic Behavior and Organization 1, 39-60.

Tok, S. (2011). The big five personality traits and risky sport participation. Social Behavior and Personality: an international journal, 39(8), 11051111.

Tsaur, S. H., Lin, C. T., \& Wu, C. S. (2005). Cultural differences of service quality and behavioral intention in tourist hotels. Journal of Hospitality \& Leisure Marketing, 13(1), 41-63.

Unzicker, D. K. (1999). The psychology of being put on hold: An exploratory study of service quality. Psychology \& Marketing, 164, 327-350.

Villi, B., \& Koc, E. (2018). Employee attractiveness and customers' service failure perceptions. Journal of Hospitality Marketing \& Management, 27(1), 4160.

Weiner, B. (2000). Intrapersonal and interpersonal theories of motivation from an attributional perspective. Educational Psychology Review, 121, $1-14$.

Williams, A. M., \& Baláž, V. (2013). Tourism, risk tolerance and competences: Travel organization and tourism hazards. Tourism Management, 35, 209-221.

Zeithaml, V. A. (1981). How consumers' evaluation processes differ between goods and services. In J. H. Donnelly, \& W. R. George (Eds.), Marketing of services (pp. 186-190). Chicago: American Marketing Association. 


\title{
INFO PAGE \\ Transformation of tourism and hospitality customers' perception of risk and customers' needs for control
}

\begin{abstract}
Although tourism and hospitality have transformed to be much safer activities compared with the past with the developments in transportation and information technologies, they still involve many risks. This review paper explains and discusses the influence of the perception of risk on consumer behaviour in tourism and hospitality and strategies that can be used to reduce consumers' risk perceptions. As eliminating or reducing consumers' risk perceptions help tourism and hospitality businesses attract more customers and maintain them, understanding concepts of risk and control may enable tourism and hospitality businesses to establish competitive advantage over their competitors. With this background in mind, the study introduces the concept of risk and the types of risks that may be associated with tourism and hospitality activities. The study also explains factors such as personality, personal characteristics which may influence customers' risk perceptions, and how these influences may take place in various contexts. Then, the study explains the theory of control and types of control which may be used to reduce consumers' risk perceptions.
\end{abstract}

Keywords: Risk perception, uncertainty, hospitality, types of risks, control, culture, personality

\section{Authors}

Full Name Author contribution roles

Erdoğan Koç: Methodology, Resources, Writing - Original Draft, Visualization,

Contribution rate

Bilge Villi: Validation, Resources, Writing - Review \& Editing,

Author statement: Author(s) declare(s) that All procedures performed in studies involving human participants were in accordance with the ethical standards of the institutional and/or national research committee and with the 1964 Helsinki declaration and its later amendments or comparable ethical standards. Declaration of Conflicting Interests: The author(s) declared no potential conflicts of interest with respect to the research, authorship, and/or publication of this article

This paper does not required ethics committee report

Justification: The methodology of this study does not require an ethics committee report. 